\title{
Efficacy of the low FODMAP diet for treating irritable bowel syndrome: the evidence to date
}

This article was published in the following Dove Press journal:

Clinical and Experimental Gastroenterology

17 June 2016

Number of times this article has been viewed

\author{
Wathsala S Nanayakkara' \\ Paula ML Skidmore' \\ Leigh O'Brien² \\ Tim J Wilkinson ${ }^{3}$ \\ Richard B Gearry ${ }^{3}$ \\ 'Department of Human Nutrition, \\ University of Otago, Dunedin, \\ New Zealand; 'Dietary Specialists, \\ Christchurch, New Zealand; \\ ${ }^{3}$ Department of Medicine, University \\ of Otago, Christchurch, New Zealand
}

Correspondence: Richard B Gearry Department of Medicine, University of Otago, 2 Riccarton Avenue, Christchurch 8140, New Zealand

Tel +643364 I567

Fax +6333640920

Email Richard.Gearry@cdhb.health.nz

\begin{abstract}
This review summarizes the published clinical studies concerning the management of irritable bowel syndrome (IBS) using restriction of Fermentable Oligosaccharide, Disaccharide, Monosaccharide, and Polyols in the diet (low FODMAP diet). In recent years, the data supporting low FODMAP diet for the management of IBS symptoms have emerged, including several randomized controlled trials, case-control studies, and other observational studies. Unlike most dietary manipulations tried in the past to alleviate gastrointestinal symptoms of IBS, all studies on low FODMAP diet have consistently shown symptomatic benefits in the majority of patients with IBS. However, dietary adherence by the patients and clear dietary intervention led by specialized dietitians appear to be vital for the success of the diet. Up to $86 \%$ of patients with IBS find improvement in overall gastrointestinal symptoms as well as individual symptoms such as abdominal pain, bloating, constipation, diarrhea, abdominal distention, and flatulence following the diet. FODMAP restriction reduces the osmotic load and gas production in the distal small bowel and the proximal colon, providing symptomatic relief in patients with IBS. Long-term health effects of a low FODMAP diet are not known; however, stringent FODMAP restriction is not recommended owing to risks of inadequate nutrient intake and potential adverse effects from altered gut microbiota. In conclusion, the evidence to date strongly supports the efficacy of a low FODMAP diet in the treatment of IBS. Further studies are required to understand any potential adverse effects of long-term restriction of FODMAPs.
\end{abstract}

Keywords: irritable bowel syndrome, low FODMAP diet, gastrointestinal symptoms

\section{What is irritable bowel syndrome?}

Irritable bowel syndrome (IBS) is a chronic gastrointestinal (GI) disorder characterized by symptoms of abdominal pain, bloating, and altered bowel habit such as constipation, diarrhea, or both. ${ }^{1}$ It is the most common GI condition seen by general practitioners $^{2}$ and accounts for up to $50 \%$ of patients seen in gastroenterology clinics. ${ }^{3}$ IBS is a clinical diagnosis and is made using symptom-based criteria such as Rome III criteria $^{4}$ (the current gold standard for IBS diagnosis [Table 1]) in addition to the exclusion of any organic disease. ${ }^{5}$ Although the exact cause of IBS is unknown, there are increasing insights concerning the possible etiology and pathophysiology of IBS. These include heightened pain sensitivity or visceral hypersensitivity, ${ }^{6,7}$ abnormal gut motility, ${ }^{8}$ small intestinal bacterial overgrowth, ${ }^{9}$ low-grade intestinal inflammation, ${ }^{10}$ psychosocial factors, ${ }^{11}$ and dysregulated gut-brain axis. ${ }^{12,13}$ Thus, IBS appears to be a multifactorial, albeit incompletely understood, disorder.

The global IBS prevalence is $10 \%-20 \%$ depending on the diagnostic criteria used and the geographic region. ${ }^{14}$ The varying prevalence of IBS among countries may be work you hereby accept the Terms. Non-commercial uses of the work are permitted without any further (ermission from Dove Medical Press Limited, provided the work is properly attributed. For permission for commercial use of this work, please see paragraphs 4.2 and 5 of our Terms (https://www.dovepress.com/terms.php). 
Table I Rome III diagnostic criteria for irritable bowel syndrome ${ }^{4}$

Recurrent abdominal pain or discomfort ${ }^{\mathrm{a}}$ at least 3 days per month in the last 3 months ${ }^{b}$ associated with two or more of the following:

I. Improvement with defecation

2. Onset associated with a change in frequency of stool

3. Onset associated with a change in form (appearance) of stool

Notes: ${ }^{a}$ Discomfort is an uncomfortable sensation not described as pain. ${ }^{\mathrm{b}} \mathrm{Criteria}$ fulfilled for the last 3 months with symptom onset of at least 6 months prior to diagnosis. Reprinted from Gastroenterology, 130(5), Longstreth GF, Thompson WG, Chey WD, Houghton LA, Mearin F, Spiller RC, Functional bowel disorders, 1480I49I, Copyright (2006), with permission from Elsevier.

due to variable application of the diagnostic criteria, demographic differences, and other factors such as health care utilization, health beliefs, or diet..$^{14,15}$ IBS is also more common in women than in men and in individuals below the age of 50 years. ${ }^{14}$ IBS can be subclassified into IBS with diarrhea (IBS-D), IBS with constipation (IBS-C), mixed IBS (IBS-M), or unsubtyped (IBS-U) based on their predominant bowel pattern. ${ }^{4}$ IBS is associated with high health care costs ${ }^{16,17}$ as well as impaired quality of life (QoL), compared to the general population. ${ }^{18-20}$ The QoL also compares poorly with other chronic conditions such as gastroesophageal reflux disease, diabetes mellitus, and end-stage renal disease. ${ }^{18}$

The main treatment goal for clinicians treating patients with IBS is to alleviate global GI symptoms; however, because of the multiple symptoms described by patients with IBS, this is often challenging. While an effective physician-patient relationship is considered the cornerstone for effective treatment, ${ }^{21}$ a combination of pharmaceutical and nonpharmaceutical approaches are now considered. However, the traditional pharmacological treatments such as bulking agents, anticholinergics, antispasmodics, and antidiarrheals often do not provide adequate symptomatic relief in patients with IBS if used alone. ${ }^{22,23}$ A more holistic approach using nonpharmacological therapies such as dietary manipulation, exercise, cognitive-behavioral therapy, and hypnotherapy seems to provide further benefits in these patients. ${ }^{24}$ The "Diet as a therapy for IBS" section discusses some of the dietary manipulations aimed at improving the global symptoms of IBS.

\section{Diet as a therapy for IBS}

Nearly two-thirds of patients with IBS perceive their GI symptoms to be food-related. ${ }^{25}$ Incompletely absorbed carbohydrates (found in foods such as lactose found in dairy products, beans, onion, cabbage, apples, and wheat) as well as fatty foods, coffee, alcohol, and spicy foods have all been found to trigger or aggravate GI symptoms..$^{25,26}$
Many early studies focused on strict exclusion or elimination diets followed by food rechallenge to investigate the role of food intolerance in patients with IBS. For example, 25 consecutive patients diagnosed with IBS-D were asked to limit their diets to a single meat, a single fruit, and distilled or spring water for 1 week. ${ }^{27}$ Fourteen (67\%) of those who completed the diet were symptom free. ${ }^{27}$ Six out of 14 patients then underwent a randomized double-blind food challenge in which participants were fed a liquidized preparation of either a test food (believed to provoke symptoms) or a control food via a nasogastric tube, and food intolerance was confirmed. ${ }^{27}$ McKee et $\mathrm{al}^{28}$ repeated the dietary limitation component of this study including other subtypes of IBS and found that only $6 / 40(15 \%)$ patients with IBS had symptomatic improvement (mostly in IBS-D). In another study, nearly half (91/189) of a cohort of female patients with IBS experienced symptomatic improvement after 3 weeks of a strict exclusion diet without dairy products, cereals, citrus fruits, potatoes, tea, coffee, alcohol, additives, and preservatives, while the remainder (98/189) found no improvement. ${ }^{29}$ Parker et al ${ }^{30}$ described a similar but nutritionally adequate exclusion diet where alternative foods to those that were being excluded were suggested to participants. However, only 39 of 96 (41\%) patients with IBS who completed the 2-week exclusion diet improved. ${ }^{30}$ The variability in responses to these exclusion diets is likely due to differences in study protocols including duration of exclusion diet, the types of foods excluded, as well as the subtypes of IBS participants recruited in the study. Welldesigned randomized control trials have been lacking when it comes to the investigation of many such exclusion diets. However, designing controlled dietary intervention studies is difficult, particularly with regard to blinding study participants. Given that placebo response rates in IBS trials may be as high as $40 \%,{ }^{31}$ difficulties in blinding can be a significant source of bias.

Lactose malabsorption resulting from lactase deficiency is known to cause abdominal pain, flatulence, and loose bowel motions. Hypolactasia or lactase deficiency is generally due to primary or secondary deficiency since congenital lactase deficiency at birth is extremely rare. ${ }^{32}$ Approximately $70 \%$ of the world population have primary lactose deficiency resulting from loss of lactase activity, which begins between the ages of 2 and 6 years, ${ }^{33}$ whereas secondary lactase deficiency often occurs as a result of GI illness such as viral gastroenteritis or celiac disease. ${ }^{32}$ Some studies have investigated the role of low lactose diet in the management of IBS with mixed results. In one study, $27 \%$ of 122 patients with IBS were found to have lactose malabsorption with positive lactose hydrogen 
breath test; however, only nine (39\%) had improvement in their symptoms following the low lactose diet. ${ }^{34}$ In contrast, Böhmer et $\mathrm{al}^{35}$ found a marked reduction in symptoms with a lactose-restricted diet in patients with IBS with lactose malabsorption (24\%) diagnosed with a hydrogen breath test, but no improvement in patients with IBS who tested negative for lactose malabsorption. Therefore, although conflicting, the results concerning lactose malabsorption and restriction suggest that lactose restriction should be tried in patients with IBS in whom lactose malabsorption is proven but that other dietary restrictions may also be required.

Probiotics, a food supplement of a single live microbe or mix of microbes with beneficial properties, is another dietary treatment that has been studied extensively in both IBS and also many other conditions. A systematic review and meta-analysis of 14 randomized control trials of probiotics in patients with IBS found a modest improvement in overall symptoms with probiotic use for several weeks (odds ratio, 1.6;95\% confidence interval, 1.2-2.2). ${ }^{36}$ However, given that each probiotic may have different characteristics, including variable effects on cytokines, host microbiota, and other potential targets, it is likely that the effects will be specific to each probiotic rather than the entire class.

In fiber supplementation studies, soluble fiber (psyllium) ${ }^{37}$ but not insoluble fiber (bran) $)^{37,38}$ was found to be effective in the management of patients with IBS. In fact, bran supplementation led to worsened symptoms in $55 \%$ of the patients. ${ }^{38}$ A small study of 13 overweight or obese participants with IBS-D who completed the study found significant improvement in their stool consistency, pain, and QoL with a very low-carbohydrate diet (20 g carbohydrates/d); ${ }^{39}$ however, larger studies including patients with normal body mass index are needed to confirm these results.

A double-blind, randomized, placebo-controlled rechallenge trial of gluten in patients with IBS resulted in significantly worse overall symptoms of pain, bloating, and stool consistency in the gluten group (who received gluten-containing foods) compared to the placebo group. ${ }^{40}$ Interestingly, a subsequent double-blinded crossover trial in subjects with nonceliac gluten sensitivity (NCGS) and IBS without celiac disease performed by the same group found no evidence of specific or dose-dependent effects of gluten, while improvements in symptoms were seen with a diet low in fermentable carbohydrates (Fermentable Oligosaccharide, Disaccharide, Monosaccharide, and Polyols [FODMAPs] $).{ }^{41}$ This study ${ }^{41}$ suggests that the carbohydrate component (fructans and galacto-oligosaccharides) of the wheat as opposed to the gluten may be responsible for the
IBS symptoms experienced by patients with NCGS and IBS. Thus, it may be that a combination of incompletely absorbed carbohydrates may be responsible for eliciting many symptoms of IBS rather than one specific food or food component.

\section{The low FODMAP diet}

FODMAPs are a group of carbohydrates that are poorly absorbed in the small intestine and subsequently fermented in the small or large intestine. ${ }^{42}$ These poorly absorbed short-chain carbohydrates include fructose and lactose (in patients who malabsorb these with impaired enzyme activity or transport mechanisms), fructans, galacto-oligosaccharides, and polyols or sugar alcohols. Table 2 lists representative examples of common foods that are known to be high in FODMAPs and examples of suitable low FODMAP alternatives. The implementation of low FODMAP diet is beyond the scope of this paper, but it is covered in detail elsewhere. ${ }^{43,44}$

\section{How does a low FODMAP diet work in IBS?}

Not all FODMAPs exacerbate abdominal symptoms in patients with IBS. The presence and degree of abdominal symptoms in a given individual depends on the degree of malabsorption experienced by the individual. There are two main mechanisms responsible for the induction of symptoms in patients with IBS by FODMAPs. First, FODMAPs are poorly absorbed by the small intestine and are osmotically active, leading to net secretion of fluid into the small intestine. This may distend the small intestine, leading to abdominal symptoms, in addition to increasing water delivered to the colon. In a study of ileostomates, ${ }^{45}$ intestinal output was increased by $22 \%$ with high consumption of FODMAPs within meals secondary to an increased osmotic load. In addition, a recent magnetic resonance imaging study has shown an abnormal accumulation of fluid in the small intestine of patients with IBS following ingestion of an unabsorbed carbohydrate, lactulose, as well as provoking significantly more symptoms compared to healthy controls. ${ }^{46}$ These results support the underlying mechanism leading to diarrhea experienced by some patients with IBS. Second, FODMAPs are rapidly fermented by the colonic microbiota, leading to colonic distention from gas production, with associated pain and bloating. A reduction in breath hydrogen production, which measures the degree of gas produced by the microbiota, in both healthy and IBS subjects with a low FODMAP diet has been shown in a recent study, suggesting reduced fermentation and gas production with restriction of poorly absorbed carbohydrates. ${ }^{47}$ Subsequently, there was an 
Table 2 Examples of food high in FODMAPs and suitable low FODMAP alternatives

\begin{tabular}{|c|c|c|}
\hline Types of sugars & High FODMAPs food & Low FODMAP alternatives \\
\hline Oligosaccharides & $\begin{array}{l}\text { FOS } \\
\text { Grains: wheat-, rye-, and barley-based products } \\
\text { Vegetables: onion, garlic, artichokes, leeks, beetroot, } \\
\text { and savoy cabbage } \\
\text { Fruits: watermelon, peaches, persimmon, prunes, } \\
\text { nectarines and most dried fruit } \\
\text { GOS } \\
\text { Legumes: red kidney beans, baked beans, and soya beans } \\
\text { Vegetables: beetroot and peas }\end{array}$ & $\begin{array}{l}\text { Fruit: banana, most berries (except boysenberries } \\
\text { and blackberries), grapes, lemon, lime, mandarin, } \\
\text { orange, kiwi fruit, pineapple, passion fruit, and } \\
\text { rhubarb } \\
\text { Vegetables: capsicum, bok choy, green beans, } \\
\text { parsnip, silverbeet, cucumber, carrots, celery, } \\
\text { eggplant, lettuce, potatoes, yams, tomatoes, and } \\
\text { zucchini } \\
\text { Grains: wheat-free grains/flour, gluten-free bread or } \\
\text { cereal products, and quinoa }\end{array}$ \\
\hline Disaccharides & $\begin{array}{l}\text { Lactose } \\
\text { Dairy products: cows/goat milk, and yoghurt }\end{array}$ & $\begin{array}{l}\text { Dairy products: lactose-free, almond or rice-based } \\
\text { milk, yoghurt and ice cream, hard cheese, feta and } \\
\text { cottage cheese }\end{array}$ \\
\hline Monosaccharides & $\begin{array}{l}\text { Fructose (in excess of glucose) } \\
\text { Fruits: apples, pears, watermelon, mango, cherries, } \\
\text { boysenberries and fruit juice from high-fructose foods } \\
\text { Honey } \\
\text { Sweeteners: high-fructose corn syrup } \\
\text { Vegetable: asparagus and snap peas }\end{array}$ & $\begin{array}{l}\text { Fruit: banana, grapes, honeydew, melon, kiwifruit, } \\
\text { lemon, lime, mandarin, orange, passionfruit, paw } \\
\text { paw, and most berries (except boysenberries and } \\
\text { blackberries) } \\
\text { Sweeteners: maple syrup and golden syrup }\end{array}$ \\
\hline Polyols & $\begin{array}{l}\text { Sorbitol } \\
\text { Fruit: apples, pears, avocado, apricots, blackberries, } \\
\text { nectarines, peaches, plums, prunes, and watermelon } \\
\text { Mannitol } \\
\text { Vegetables: sweet potato, mushrooms, cauliflower, } \\
\text { and snow peas }\end{array}$ & $\begin{array}{l}\text { Sweeteners: Maple syrup, and sugar (sucrose) } \\
\text { Fruits: banana, grape, honeydew, melon, kiwifruit, } \\
\text { lemon, mandarin, orange, passionfruit, and paw paw }\end{array}$ \\
\hline
\end{tabular}

Notes: Data from Monash University. Low FODMAP Diet Application. Available at: http://www.med.monash.edu/cecs/gastro/fodmap/. Android version accessed August 26, 2015. ${ }^{72}$

Abbreviations: FODMAP, fermentable oligosaccharide, disaccharide, monosaccharide, and polyols; FOS, fructo-oligosaccharides; GOS, galacto-oligosaccharides.

improvement of GI symptoms in the patients with IBS on a low FODMAP diet. ${ }^{47}$ Thus, the study supports the hypothesis that rapid fermentation of undigested, unabsorbed FODMAPs in the colon results in distention of the large bowel, bloating, and abdominal pain from excess gas production.

\section{Clinical studies of low FODMAP diet and IBS}

Studies on the effect of dietary restriction of FODMAPs in patients with IBS have shown consistent results supporting the efficacy of the low FODMAP diet in improving overall GI symptoms of adult patients with IBS (Tables 3 and 4). However, as noted earlier, designing and implementing a prospective placebo-controlled dietary intervention study are extremely difficult. In the field of a low FODMAP diet in the treatment of IBS symptoms, many studies are retrospective ${ }^{48,49}$ or prospective and uncontrolled, ${ }^{47-53}$ making the studies potentially subject to bias and confounding. To date, there have been two controlled trials ${ }^{49,54}$ and six randomized controlled trials ${ }^{47,55-59}$ evaluating low FODMAP diet in patients with IBS. These studies, and others described in Tables 3 and 4 were conducted in Australia (four), Norway (two), Denmark (two), New Zealand (one), Switzerland (one), Sweden (one), and the UK (two).

The majority of studies comprised a small number of participants (fewer than 100), ${ }^{47,48,50,52,54,56-58,60}$ and two of the studies ${ }^{50,51}$ had poor study completion or response rates $(<50 \%)$. The average age of IBS participants ranged from 35 to 50 years and, as one might expect with an IBS cohort, a large proportion of the participants were female $(66 \%-87 \%)$ in all studies. ${ }^{47-54,56-60}$ The common primary outcome measure was changes in GI symptoms (overall and/ or individual symptoms); however, the use of scoring scales varied considerably with a few studies using validated questionnaires. ${ }^{49,50,54,56}$ While not all studies assessed for dietary intake, the dietary assessment methodologies included food frequency questionnaire, ${ }^{49,50}$ food diaries, ${ }^{47,55,56,58}$ and other unspecified methods. ${ }^{53}$ Dietary advice on a low FODMAP diet was mostly delivered by a specialized or trained dietitian, with the exception of two studies where a registered nurse had provided the dietary guidance. ${ }^{49,50}$ Not all studies provided the list of foods allowed in the low FODMAP diet; however, two studies ${ }^{49,50}$ allowed peeled apples, pears, and milk as part of the low FODMAP diet, which is not consistent 


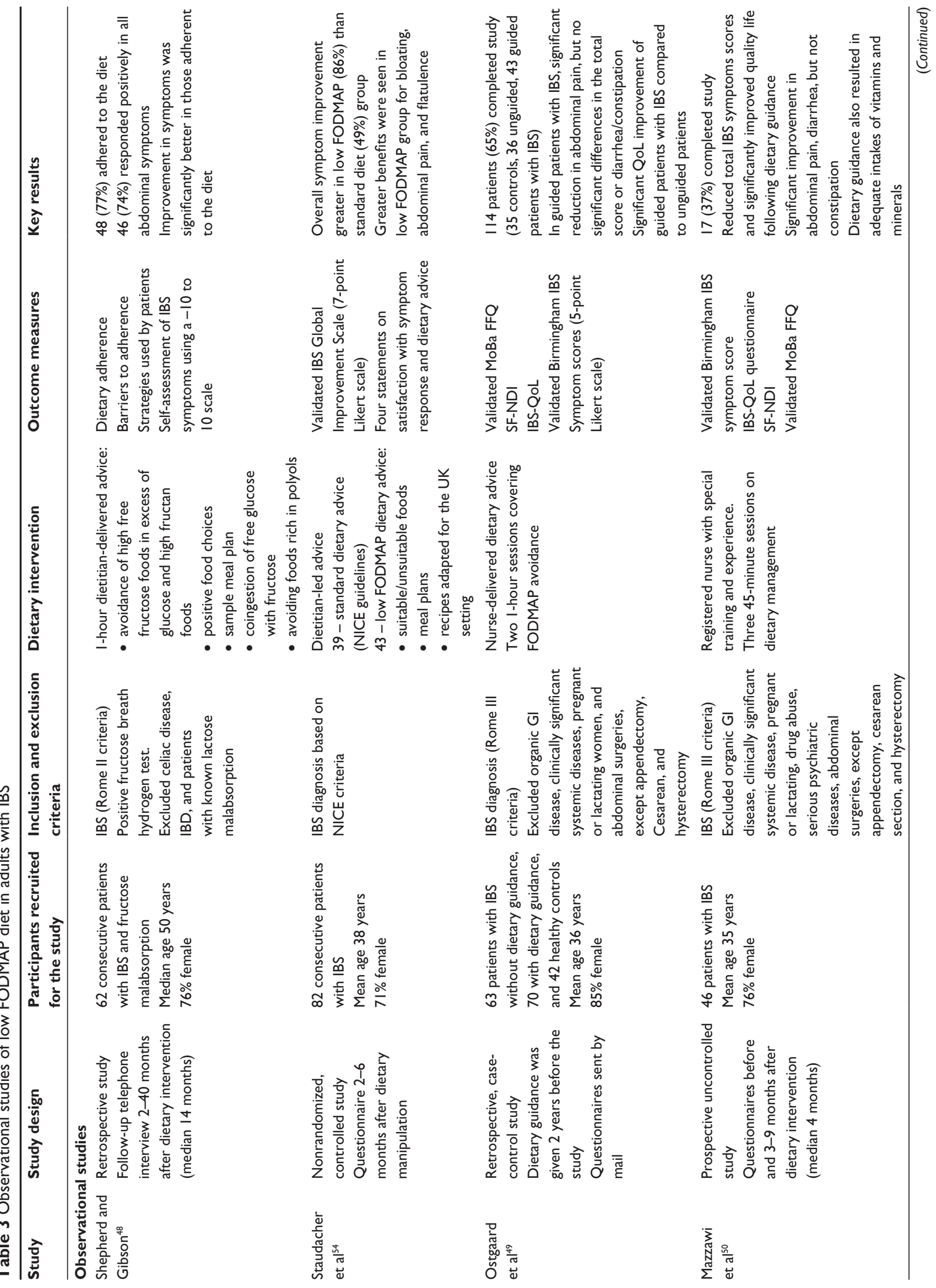




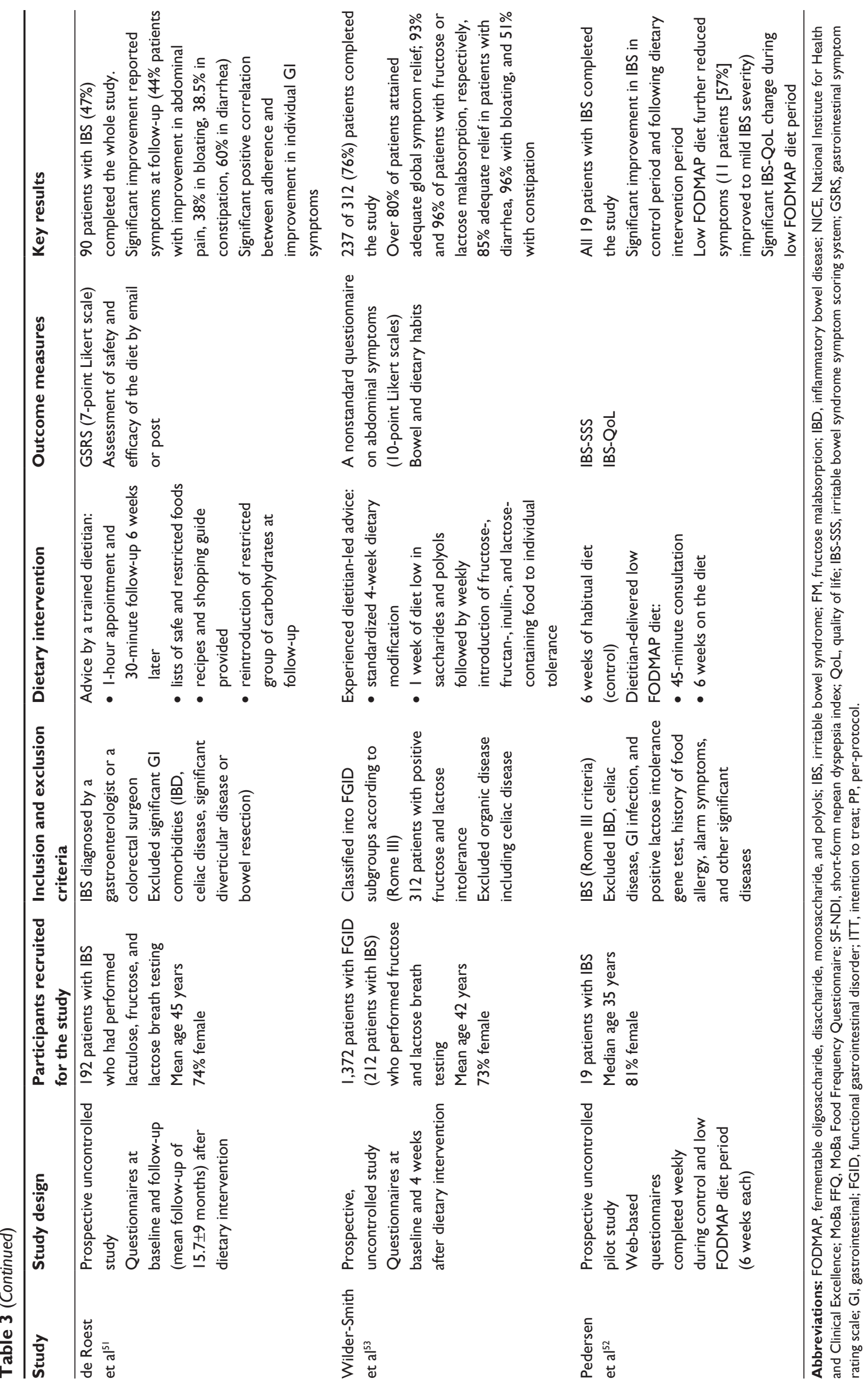




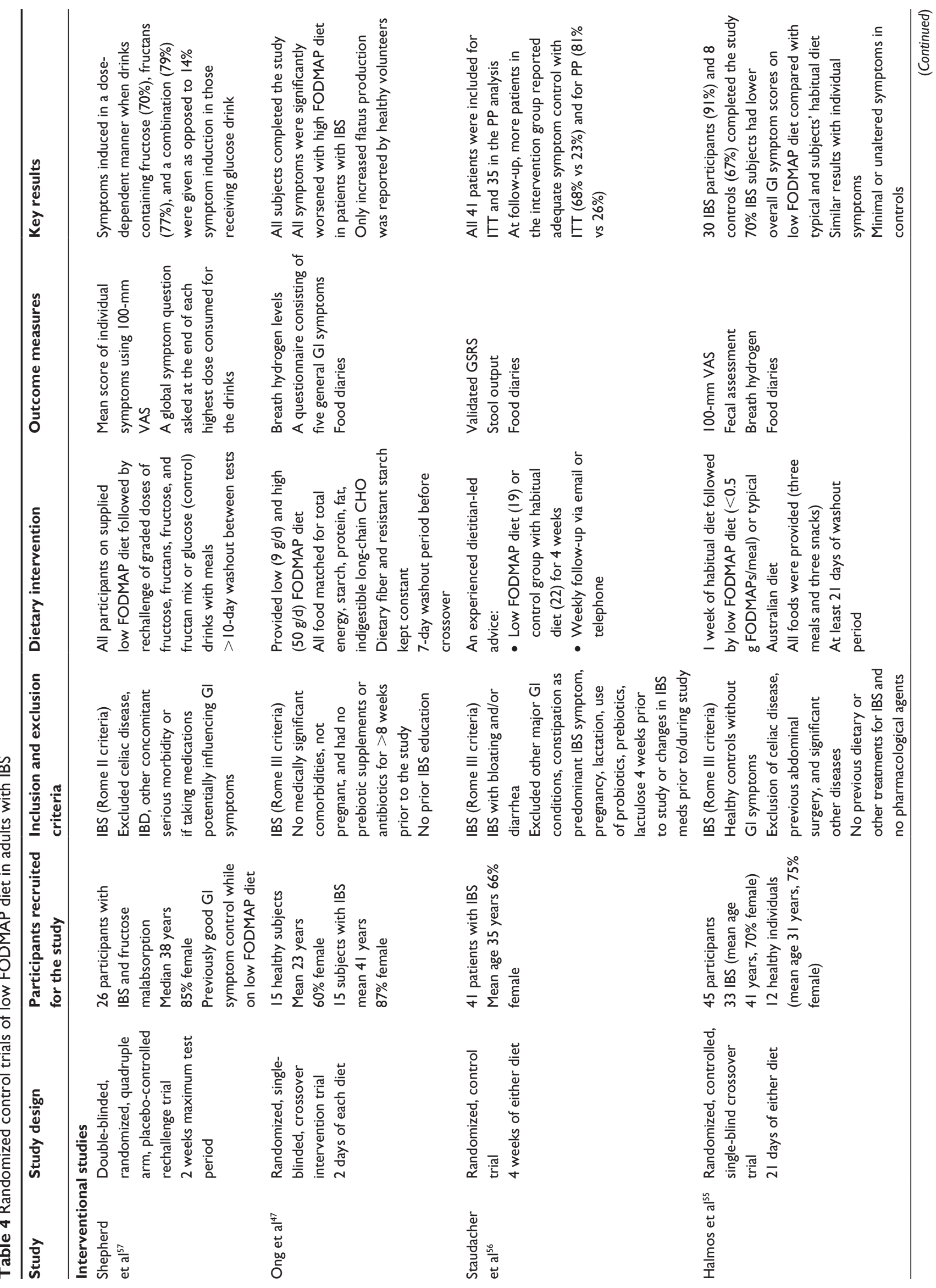




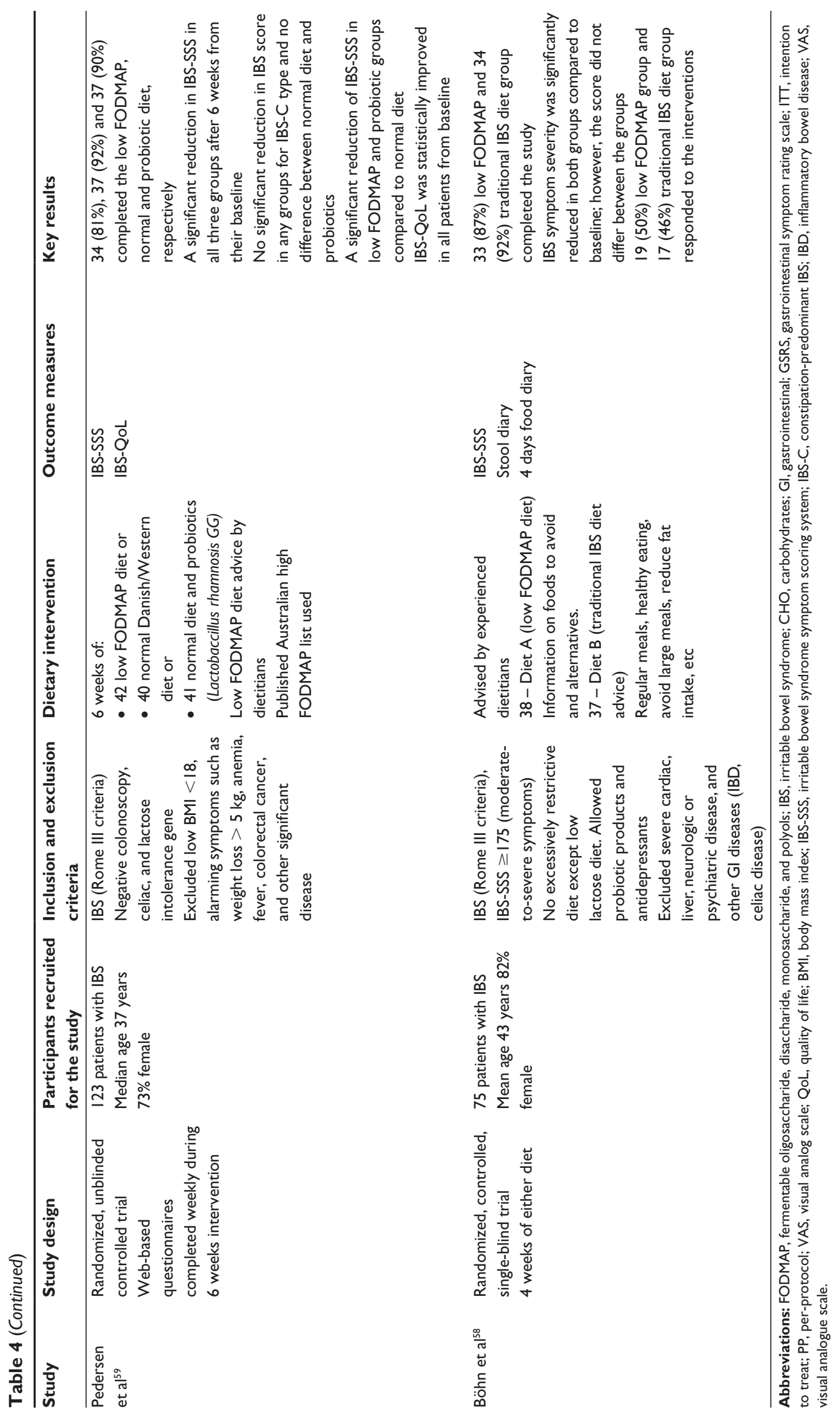


with a low FODMAP diet as it has been described. Since the first low FODMAP diets were described, ${ }^{48}$ there have been modifications to the food lists that have been prompted by new scientific data on food composition. However, robust data now exist describing the FODMAP content of commonly consumed foods (Table 2).

Randomized, double-blind, placebo-controlled studies are considered the "gold standard" for an intervention study; ${ }^{61}$ however, this is almost impossible to apply in dietary interventions. The more recent study conducted by Halmos et $\mathrm{al}^{55}$ was a randomized controlled, single-blind crossover study in which 30 IBS and 9 healthy subjects consumed 21 days of low FODMAP diet or the typical Australian diet. The authors were able to address confounding variables by providing all intervention diets that were matched for all nutrients except for the FODMAP content. They found that $70 \%$ of IBS subjects (across all four subtypes of IBS) felt better on the low FODMAP diet, whereby the greatest symptom control was achieved and maintained after 7 days on the low FODMAP diet.

Additional evidence supporting FODMAPs as "food triggers" was provided in a randomized, placebo-controlled, rechallenge trial in 25 patients with IBS with fructose malabsorption. ${ }^{57}$ In this study, a dose-dependent induction of GI symptoms was seen in the majority of patients with IBS following introduction of fructose (70\%), fructans (77\%), and fructose and fructans mix (79\%) compared to glucose $(14 \%)$ in liquid forms following a low FODMAP diet. This study also supports cumulative and dose-dependent effects of FODMAPs on inducing GI symptoms in patients with IBS.

Most patients with IBS find the diet easy to adhere to, ${ }^{51,54}$ with better symptomatic improvement seen in those with the best adherence. ${ }^{48,51}$ A randomized controlled trial conducted by Pedersen et $\mathrm{a}^{59}$ found that the low FODMAP diet as well as the probiotics had significantly improved the IBS symptom score compared to the normal diet. However, this study was unblinded, and all three groups had a significantly improved symptom score after 6 weeks of intervention and web-based self-monitoring of symptoms compared to the baseline. ${ }^{59}$

Furthermore, the low FODMAP diet has provided symptomatic relief in more patients with IBS compared to a standard dietary advice consisting of healthy eating principles, alteration of insoluble and soluble fibers, and limiting sugar-free foods and foods containing sorbitol (86\% and $49 \%$, respectively). ${ }^{54} \mathrm{~A}$ recent single-blinded randomized controlled trial ${ }^{58}$ comparing the low FODMAP diet and the traditional dietary advice of regular meal pattern, avoiding or limiting certain foods such as fat, insoluble fiber, caffeine, and "windy vegetables" found reduced severity of symptoms in both groups, but no significant difference between the intervention groups. It was noted, however, the excess fructose intake was significantly lower in the traditional IBS diet group at the end of their study compared to baseline.

Limitations of low FODMAP diet include lack of clear cutoff levels for FODMAP content in foods and nonavailability of information on FODMAP content on food packages. However, research is being carried out to compile a comprehensive nutrient composition database for FODMAPs. Because the diet is fairly complex, advice should be given by a specialized dietitian trained in the area with appropriate resources, and food intake should be monitored for nutritional adequacy. Compliance may be a factor; nonetheless, the low FODMAP diet does not appear to alleviate GI symptoms of every IBS subject. Furthermore, the health effects of long-term low FODMAP diet are unknown. Human intestinal microbiota plays a critical role in health and disease. Although inulin-type fructans and galacto-oligosaccharides are FODMAPs, the ingestion of which may be associated with abdominal symptoms, they are also prebiotics, stimulating the growth of beneficial bacteria. ${ }^{62}$ Studies have shown reduced total bacterial abundance ${ }^{60}$ and reduced concentration of bifidobacteria $^{56}$ following a low FODMAP diet, suggesting potential adverse health effects of the diet. Generally, the strict low FODMAP diet is not recommended to be followed long term. Reintroduction or rechallenge of FODMAP foods is recommended based on individual tolerance. ${ }^{63}$

There are few low FODMAP dietary intervention studies conducted in children (not included in Tables 3 and 4). Until recently, these studies have focused on lactose malabsorption only. ${ }^{64,65}$ More recently, a pilot study ${ }^{66}$ and a randomized study ${ }^{67}$ have shown reduction in abdominal pain frequency in children between 7 and 17 years of age with the low FODMAP diet. The results from these studies have also suggested that a difference in the microbiome composition at baseline may determine responders and nonresponders to the low FODMAP diet. Specifically, the responders had bacteria with greater saccharolytic capacity (such as genera Sporobacter and Subdoligranulum ${ }^{66}$ and Bacteroids, Ruminococcaceae, and Faecalibacterium prausnitzii) ${ }^{67}$ at baseline to break down sugars than those who did not respond to the diet. Hence, reduction in GI symptoms in children with IBS was seen with the low FODMAP diet likely due to decrease in osmotic load and gas production from fermentation.

In general, nearly all of the studies have used the Rome diagnostic criteria to select patients with IBS, which have resulted in a predominance of female subjects mostly between the ages of 30 and 50 years. The design of the studies varied 
largely in terms of duration and the delivery of dietary intervention as well as symptom scoring tools or scales used. In all studies, however, improvements in overall GI symptoms were evident with those following a low FODMAP diet. Although the results are not consistent, significant improvements in diarrhea and constipation were seen in most studies. However, standardized dietary interventions and outcome measures were not used and are required to allow robust comparison in future studies. Finally, the first meta-analysis published in $2015^{68}$ supports the efficacy of the diet in the treatment of functional GI symptoms including IBS.

\section{Low FODMAP diet in other diseases}

There are some studies in which low FODMAP diet has been applied to improve other lower GI disorders. For example, functional gut symptoms or IBS-type symptoms are common in patients with inflammatory bowel disease (IBD), with a greater prevalence seen in Crohn's disease than in patients with ulcerative colitis. ${ }^{69}$ Gearry et $\mathrm{al}^{70}$ have demonstrated that restriction in FODMAPs improved overall abdominal symptoms as well as abdominal pain, bloating, wind, and diarrhea in patients with IBD in a retrospective study. Similarly, reduction in dietary FODMAPs intake improved stool output and consistency in patients with ulcerative colitis following ileorectal anastomosis or ileal pouch formation and colectomy. ${ }^{71}$ Both of these studies have shown improvement with good adherence to the diet. As mentioned earlier in this review, significant improvements in GI symptoms were also seen in NCGS subjects with IBS $^{41}$ and in all other types of patients with functional GI disorder. ${ }^{69}$

\section{Future directions}

Standardized dietary intervention in low FODMAP diet intervention studies and the use of validated symptom scales as predefined primary outcomes are essential to ensure that the results may be generalizable across larger and more diverse populations. Furthermore, modifications of the low FODMAP diet to individual tolerance should be considered in order to test the true efficacy of low FODMAP diet in long-term management of IBS. Finally, the long-term effect of a low FODMAP diet on the colonic health, particularly the microbiome, requires further investigation.

\section{Conclusion}

In summary, the evidence to date indicates that restriction of FODMAPs is an effective dietary intervention for reducing IBS symptoms. There are now well-designed clinical trials to support the efficacy of low FODMAP diet with alleviation of GI symptoms in majority of patients with IBS. More studies are required to assess long-term efficacy of low FODMAP diet following food rechallenge and to ascertain any adverse outcomes from effects on the gut microbiota.

\section{Disclosure}

The authors report no conflicts of interest in this work.

\section{References}

1. Fass R, Longstreth GF, Pimentel M, et al. Evidence- and consensusbased practice guidelines for the diagnosis of irritable bowel syndrome. Arch Intern Med. 2001;161(17):2081-2088.

2. Thompson WG, Heaton KW, Smyth GT, Smyth C. Irritable bowel syndrome in general practice: prevalence, characteristics, and referral. Gut. 2000;46(1):78-82.

3. Harvey RF, Salih SY, Read AE. Organic and functional disorders in 2000 gastroenterology outpatients. Lancet. 1983;1(8325):632-634.

4. Longstreth GF, Thompson WG, Chey WD, Houghton LA, Mearin F, Spiller RC. Functional bowel disorders. Gastroenterology. 2006; 130(5):1480-1491.

5. Camilleri M. Management of the irritable bowel syndrome. Gastroenterology. 2001;120(3):652-668.

6. Bueno L, Fioramonti J. Visceral perception: inflammatory and noninflammatory mediators. Gut. 2002;51(Suppl 1):i19-i23.

7. Accarino AM, Azpiroz F, Malagelada JR. Selective dysfunction of mechanosensitive intestinal afferents in irritable bowel syndrome. Gastroenterology. 1995;108(3):636-643.

8. Kellow JE, Eckersley GM, Jones M. Enteric and central contributions to intestinal dysmotility in irritable bowel syndrome. Dig Dis Sci. 1992;37(2):168-174.

9. Lin HC. Small intestinal bacterial overgrowth: a framework for understanding irritable bowel syndrome. JAMA. 2004;292(7):852-858.

10. Barbara G, De Giorgio R, Stanghellini V, Cremon C, Corinaldesi R. A role for inflammation in irritable bowel syndrome? Gut. 2002; 51(Suppl 1):i41-i44.

11. Drossman DA, McKee DC, Sandler RS, et al. Psychosocial factors in the irritable bowel syndrome. A multivariate study of patients and nonpatients with irritable bowel syndrome. Gastroenterology. 1988;95(3):701-708.

12. Tougas $\mathrm{G}$. The autonomic nervous system in functional bowel disorders. Can J Gastroenterol. 1999;13(Suppl A):15a-17a.

13. Mayer EA, Tillisch K. The brain-gut axis in abdominal pain syndromes. Annu Rev Med. 2011;62:381-396.

14. Lovell RM, Ford AC. Global prevalence of and risk factors for irritable bowel syndrome: a meta-analysis. Clin Gastroenterol Hepatol. 2012; 10(7):712e4-721e4

15. Kang JY. Systematic review: the influence of geography and ethnicity in irritable bowel syndrome. Aliment Pharmacol Ther. 2005;21(6): 663-676.

16. Longstreth GF, Wilson A, Knight K, et al. Irritable bowel syndrome, health care use, and costs: a US managed care perspective. $A m J$ Gastroenterol. 2003;98(3):600-607.

17. Creed F, Ratcliffe J, Fernandez L, et al. Health-related quality of life and health care costs in severe, refractory irritable bowel syndrome. Ann Intern Med. 2001;134(9 Pt 2):860-868.

18. Gralnek IM, Hays RD, Kilbourne A, Naliboff B, Mayer EA. The impact of irritable bowel syndrome on health-related quality of life. Gastroenterology. 2000;119(3):654-660.

19. Hahn BA, Yan S, Strassels S. Impact of irritable bowel syndrome on quality of life and resource use in the United States and United Kingdom. Digestion. 1999;60(1):77-81.

20. Frank L, Kleinman L, Rentz A, Ciesla G, Kim JJ, Zacker C. Healthrelated quality of life associated with irritable bowel syndrome: comparison with other chronic diseases. Clin Ther. 2002;24(4):675-689; discussion 674 . 
21. Drossman DA, Camilleri M, Mayer EA, Whitehead WE. AGA technical review on irritable bowel syndrome. Gastroenterology. 2002;123(6): 2108-2131.

22. Gilkin RJ Jr. The spectrum of irritable bowel syndrome: a clinical review. Clin Ther. 2005;27(11):1696-1709.

23. Halland M, Talley NJ. New treatments for IBS. Nat Rev Gastroenterol Hepatol. 2013;10(1):13-23.

24. Yoon SL, Grundmann O, Koepp L, Farrell L. Management of irritable bowel syndrome (IBS) in adults: conventional and complementary/ alternative approaches. Altern Med Rev. 2011;16(2):134-151.

25. Simrén M, Månsson A, Langkilde AM, et al. Food-related gastrointestinal symptoms in the irritable bowel syndrome. Digestion. 2001;63(2):108-115.

26. Böhn L, Störsrud S, Törnblom H, Bengtsson U, Simrén M. Self-reported food-related gastrointestinal symptoms in IBS are common and associated with more severe symptoms and reduced quality of life. Am J Gastroenterol. 2013;108(5):634-641.

27. Jones VA, McLaughlan P, Shorthouse M, Workman E, Hunter JO. Food intolerance: a major factor in the pathogenesis of irritable bowel syndrome. Lancet. 1982;2(8308):1115-1117.

28. McKee AM, Prior A, Whorwell PJ. Exclusion diets in irritable bowel syndrome: are they worthwhile? J Clin Gastroenterol. 1987;9(5): 526-528.

29. Nanda R, James R, Smith H, Dudley CR, Jewell DP. Food intolerance and the irritable bowel syndrome. Gut. 1989;30(8):1099-1104.

30. Parker TJ, Naylor SJ, Riordan AM, Hunter JO. Management of patients with food intolerance in irritable bowel syndrome: the development and use of an exclusion diet. J Hum Nutr Diet. 1995;8(3) 159-166.

31. Patel SM, Stason WB, Legedza A, et al. The placebo effect in irritable bowel syndrome trials: a meta-analysis. Neurogastroenterol Motil. 2005; 17(3):332-340

32. Lomer MC, Parkes GC, Sanderson JD. Review article: lactose intolerance in clinical practice - myths and realities. Aliment Pharmacol Ther 2008;27(2):93-103.

33. de Vrese M, Stegelmann A, Richter B, Fenselau S, Laue C, Schrezenmeir J. Probiotics - compensation for lactase insufficiency. Am J Clin Nutr. 2001;73(2 Suppl):421S-429S.

34. Parker TJ, Woolner JT, Prevost AT, Tuffnell Q, Shorthouse M, Hunter JO Irritable bowel syndrome: is the search for lactose intolerance justified? Eur J Gastroenterol Hepatol. 2001;13(3):219-225.

35. Böhmer CJ, Tuynman HA. The clinical relevance of lactose malabsorption in irritable bowel syndrome. Eur J Gastroenterol Hepatol. 1996;8(10):1013-1016.

36. Hoveyda N, Heneghan C, Mahtani KR, Perera R, Roberts N, Glasziou P. A systematic review and meta-analysis: probiotics in the treatment of irritable bowel syndrome. BMC Gastroenterol. 2009;9:15.

37. Bijkerk CJ, de Wit NJ, Muris JW, Whorwell PJ, Knottnerus JA, Hoes AW Soluble or insoluble fibre in irritable bowel syndrome in primary care? Randomised placebo controlled trial. BMJ. 2009;339:b3154.

38. Francis CY, Whorwell PJ. Bran and irritable bowel syndrome: time for reappraisal. Lancet. 1994;344(8914):39-40.

39. Austin GL, Dalton CB, Hu Y, et al. A very low-carbohydrate diet improves symptoms and quality of life in diarrhea-predominant irritable bowel syndrome. Clin Gastroenterol Hepatol. 2009;7(6):706e1-708e1.

40. Biesiekierski JR, Newnham ED, Irving PM, et al. Gluten causes gastrointestinal symptoms in subjects without celiac disease: a double-blind randomized placebo-controlled trial. Am J Gastroenterol. 2011;106(3):508-514; quiz 515.

41. Biesiekierski JR, Peters SL, Newnham ED, Rosella O, Muir JG, Gibson PR. No effects of gluten in patients with self-reported non-celiac gluten sensitivity after dietary reduction of fermentable, poorly absorbed, short-chain carbohydrates. Gastroenterology. 2013;145(2):320-328. e321-e323.

42. Gibson PR, Shepherd SJ. Personal view: food for thought - western lifestyle and susceptibility to Crohn's disease. The FODMAP hypothesis. Aliment Pharmacol Ther. 2005;21(12):1399-1409.
43. Gibson PR, Shepherd SJ. Food choice as a key management strategy for functional gastrointestinal symptoms. Am J Gastroenterol. 2012;107(5):657-666; quiz 667.

44. Gibson PR, Shepherd SJ. Evidence-based dietary management of functional gastrointestinal symptoms: the FODMAP approach. $J$ Gastroenterol Hepatol. 2010;25(2):252-258.

45. Barrett JS, Gearry RB, Muir JG, et al. Dietary poorly absorbed, short-chain carbohydrates increase delivery of water and fermentable substrates to the proximal colon. Aliment Pharmacol Ther. 2010; 31(8):874-882.

46. Undseth R, Berstad A, Kløw NE, Arnljot K, Moi KS, Valeur J. Abnormal accumulation of intestinal fluid following ingestion of an unabsorbable carbohydrate in patients with irritable bowel syndrome: an MRI study. Neurogastroenterol Motil. 2014;26(12):1686-1693.

47. Ong DK, Mitchell SB, Barrett JS, et al. Manipulation of dietary short chain carbohydrates alters the pattern of gas production and genesis of symptoms in irritable bowel syndrome. J Gastroenterol Hepatol. 2010;25(8):1366-1373.

48. Shepherd SJ, Gibson PR. Fructose malabsorption and symptoms of irritable bowel syndrome: guidelines for effective dietary management. J Am Diet Assoc. 2006;106(10):1631-1639.

49. Ostgaard H, Hausken T, Gundersen D, El-Salhy M. Diet and effects of diet management on quality of life and symptoms in patients with irritable bowel syndrome. Mol Med Rep. 2012;5(6):1382-1390.

50. Mazzawi T, Hausken T, Gundersen D, El-Salhy M. Effects of dietary guidance on the symptoms, quality of life and habitual dietary intake of patients with irritable bowel syndrome. Mol Med Rep. 2013;8(3):845-852.

51. de Roest RH, Dobbs BR, Chapman BA, et al. The low FODMAP diet improves gastrointestinal symptoms in patients with irritable bowel syndrome: a prospective study. Int J Clin Pract. 2013;67(9):895-903.

52. Pedersen N, Vegh Z, Burisch J, et al. Ehealth monitoring in irritable bowel syndrome patients treated with low fermentable oligo-, di-, mono-saccharides and polyols diet. World J Gastroenterol. 2014;20(21):6680-6684.

53. Wilder-Smith CH, Materna A, Wermelinger C, Schuler J. Fructose and lactose intolerance and malabsorption testing: the relationship with symptoms in functional gastrointestinal disorders. Aliment Pharmacol Ther. 2013;37(11):1074-1083.

54. Staudacher HM, Whelan K, Irving PM, Lomer MC. Comparison of symptom response following advice for a diet low in fermentable carbohydrates (FODMAPs) versus standard dietary advice in patients with irritable bowel syndrome. J Hum Nutr Diet. 2011;24(5):487-495.

55. Halmos EP, Power VA, Shepherd SJ, Gibson PR, Muir JG. A diet low in FODMAPs reduces symptoms of irritable bowel syndrome. Gastroenterology. 2014;146(1):67-75.e65.

56. Staudacher HM, Lomer MC, Anderson JL, et al. Fermentable carbohydrate restriction reduces luminal bifidobacteria and gastrointestinal symptoms in patients with irritable bowel syndrome. J Nutr. 2012;142(8):1510-1518.

57. Shepherd SJ, Parker FC, Muir JG, Gibson PR. Dietary triggers of abdominal symptoms in patients with irritable bowel syndrome: randomized placebo-controlled evidence. Clin Gastroenterol Hepatol. 2008;6(7):765-771.

58. Böhn L, Störsrud S, Liljebo T, et al. Diet low in FODMAPs reduces symptoms of irritable bowel syndrome as well as traditional dietary advice: a randomized controlled trial. Gastroenterology. 2015;149(6):1399-1407.e1392.

59. Pedersen N, Andersen NN, Vegh Z, et al. Ehealth: low FODMAP diet vs Lactobacillus rhamnosus GG in irritable bowel syndrome. World $J$ Gastroenterol. 2014;20(43):16215-16226.

60. Halmos EP, Christophersen CT, Bird AR, Shepherd SJ, Gibson PR, Muir JG. Diets that differ in their FODMAP content alter the colonic luminal microenvironment. Gut. 2015;64(1):93-100.

61. Misra S. Randomized double blind placebo control studies, the "Gold Standard" in intervention based studies. Indian J Sex Transm Dis. 2012;33(2):131-134. 
62. Lin CS, Chang CJ, Lu CC, et al. Impact of the gut microbiota, prebiotics, and probiotics on human health and disease. Biomed J. 2014;37(5):259-268.

63. Tuck CJ, Muir JG, Barrett JS, Gibson PR. Fermentable oligosaccharides, disaccharides, monosaccharides and polyols: role in irritable bowel syndrome. Expert Rev Gastroenterol Hepatol. 2014;8(7):819-834.

64. Dearlove J, Dearlove B, Pearl K, Primavesi R. Dietary lactose and the child with abdominal pain. Br Med J (Clin Res Ed). 1983;286(6382):1936.

65. Lebenthal E, Rossi TM, Nord KS, Branski D. Recurrent abdominal pain and lactose absorption in children. Pediatrics. 1981;67(6):828-832.

66. Chumpitazi BP, Hollister EB, Oezguen N, et al. Gut microbiota influences low fermentable substrate diet efficacy in children with irritable bowel syndrome. Gut Microbes. 2014;5(2):165-175.

67. Chumpitazi BP, Cope JL, Hollister EB, et al. Randomised clinical trial: gut microbiome biomarkers are associated with clinical response to a low FODMAP diet in children with the irritable bowel syndrome. Aliment Pharmacol Ther. 2015;42(4):418-427.

68. Marsh A, Eslick EM, Eslick GD. Does a diet low in FODMAPs reduce symptoms associated with functional gastrointestinal disorders? A comprehensive systematic review and meta-analysis. Eur J Nutr. Epub May 17, 2015.
69. Halpin SJ, Ford AC. Prevalence of symptoms meeting criteria for irritable bowel syndrome in inflammatory bowel disease: systematic review and meta-analysis. Am J Gastroenterol. 2012;107(10):1474-1482.

70. Gearry RB, Irving PM, Barrett JS, Nathan DM, Shepherd SJ, Gibson PR. Reduction of dietary poorly absorbed short-chain carbohydrates (FODMAPs) improves abdominal symptoms in patients with inflammatory bowel disease-a pilot study. J Crohns Colitis. 2009;3(1): 8-14.

71. Croagh C, Shepherd SJ, Berryman M, Muir JG, Gibson PR. Pilot study on the effect of reducing dietary FODMAP intake on bowel function in patients without a colon. Inflamm Bowel Dis. 2007;13(12): $1522-1528$.

72. Monash University. Low FODMAP Diet Application. [Mobile app]. Available at: http://www.med.monash.edu/cecs/gastro/fodmap/.Android version. Accessed August 26, 2015.

\section{Publish your work in this journal}

Clinical and Experimental Gastroenterology is an international, peerreviewed, open access journal, publishing all aspects of gastroenterology in the clinic and laboratory, including: Pathology, pathophysiology of gastrointestinal disease; Investigation and treatment of gastointestinal disease; Pharmacology of drugs used in the alimentary tract;
Immunology/genetics/genomics related to gastrointestinal disease. This journal is indexed on CAS. The manuscript management system is completely online and includes a very quick and fair peer-review system. Visit http://www.dovepress.com/testimonials.php to read real quotes from published authors.

Submit your manuscript here: http://www.dovepress.com/clinical-and-experimental-gastroenterology-journal 